\title{
Balancing Yin and Yang: the development of a framework using Participatory Action Research for the Translation and Implementation (Part 1) of new practices
}

\author{
A Fitzgerald, R Ogrin, K Hayes, J Curry, K Eljis and K Radford
}

\begin{abstract}
Context: Despite the demonstrable benefits of many healthcare innovations, embedding research findings into practice has been slow and sporadic. [1,2] Many implementation frameworks exist, however most have been criticised for not having a strong theoretical underpinning. This study addresses this gap by reviewing the current models to propose a new, theoretically driven framework for change management and translation.

Methods: This study is reported in two parts. In part 1, a systematically-based literature review was undertaken. Following this, part 2 included conducting focus groups with academics to verify the model and provide feedback on the new framework.
\end{abstract}

Findings: The gaps in current implementation frameworks identified include deficiencies in the areas of individual and social behaviour, participatory action, operationalisation and evaluation of the frameworks. The Quality Implementation Framework (QIF) [3] was used to provide the basis to develop a robust extended model, which addressed those areas that were identified as deficient in the current frameworks. By combining the best parts of extant models with a translation and implementation foci, we developed the PARTI model that is underpinned by commitment to change (Ying) and change fidelity (Yang) at each of its four stages, which included a behavioural questionnaire and implementation checklist. PARTI stands for Participatory Action Research, Translation and Implementation.

Conclusions: The implementation of change in healthcare delivery is difficult and demanding, and healthcare managers look to change frameworks for guidance. The PARTI model has been developed to provide a systematic approach to implementing changed practices that is repeatable, reliable and scalable.

Abbreviations: ISF - Interactive Systems Framework; PAR - Participatory Action Research; PARTI - Participatory Action Research for Translation and Implementation;

QIF - Quality Implementation Framework;

TDF - Theoretical Domains Framework.

Key words: knowledge translation; evidence-based practice; organisation innovation; implementation framework; managing change; healthcare.

\section{Kathy Eljis}

University of Tasmania

Sydney, New South Wales, Australia

Griffith University

Gold Coast Campus

Southport, Queensland, Australia.

\section{Rajna Ogrin}

Royal District Nursing Service

Melbourne, Victoria, Australia.

\section{Kate Hayes}

University of Western Sydney

Sydney, New South Wales, Australia.

\section{Joanne Curry}

University of Western Sydney

Sydney, New South Wales, Australia.

\section{Katrina Radford}

Department of International Business and Asian Studies

Griffith University

Southport, Queensland, Australia.

Correspondence:

k.radford@griffith.edu.au 


\section{Background}

Despite the demonstrable benefits of many healthcare innovations, implementing clinical and operational research findings into practice has been slow and sporadic. [1,2] Improving the uptake of evidence into practice requires effective and feasible dissemination and implementation strategies, [4] underpinned by theory. [5-7] Importantly, these strategies must also be operationalised. In the context of this research, operationalisation is defined as the process of converting conceptual or abstract variables in ways that permit empirical measurement. Therefore, it is necessary to have clear descriptions of all stages and components of implementation models. This clarity ensures fidelity, that is, being as close as possible to that which was planned, and assists in adapting practice changes to each context for implementation, as well as in understanding the core components of the change. This includes understanding what is necessary to define and illustrate so they can be taught, learnt and implemented in typical health settings. This practical approach addresses the measurement of behaviours and practices that provide evidence that changes are or are not effective.

\section{Extant implementation frameworks}

A number of theoretically-based implementation frameworks have been developed to understand and improve the dissemination and uptake of evidence-based practice. [7] Other frameworks have been generated by applying theoretical constructs, observing environments in which innovations are implemented, and retrospectively identifying key aspects common to innovations that were successfully implemented. These frameworks describe implementation, using broad terms to name overriding constructs that need to be addressed for implementation to be successful: the 'what and why'. Other frameworks provide descriptions and are passive, providing very little specific and practical detail on the 'how' to put these concepts into practice, that is, their utility in causing change by operationalising strategies. [4]

Another criticism of the behavioural change and implementation frameworks to date has been the lack of theoretically driven rationales for behaviour change: instead they have been developed using practitioner or research intuition. [8-10] This intuitive approach makes it difficult to understand and analyse the processes that underlie effective interventions. [8,9] Theory driven implementation frameworks are important because the interventions are more likely to be successful in establishing direct links between the intervention and behaviour change. In addition, greater understanding of why the intervention works and how this may translate across contexts, populations and behaviours can be gained. [8] In this paper we outline the development of a new, more comprehensive implementation framework that is driven by theory to guide the change process. This paper contributes to the domain of implementation science by connecting several theoretical implementation frameworks, [3,11,12] enhancing them through the inclusion of the Participatory Action Research (PAR) model, [13] and linking them with practical tools to promote the implementation of innovations. [14-19]

\section{Methods}

\section{Part 1}

A comprehensive literature review revealed an article by Meyers et al, (2012) [3] incorporating 25 frameworks into the development of their Quality Implementation Framework (QIF). However, the Meyers et al review described articles only up until 2011. Whilst the framework and checklist included in the QIF is comprehensive, we first updated the literature review and, second, identified missing items that help identify the behavioural tipping point(s) for accepting or not accepting new behaviours at the individual, group and organisational levels. That is, a critical point in a situation, process, or system beyond which a significant and often unstoppable effect or change takes place (Merriam Webster Dictionary). Therefore, a systematically-based review of the literature was undertaken from 2011 until June 2013 , led by the second author, of the social sciences, education, management and health sciences literature, using $\mathrm{ABI}$ Inform, Pubmed, Psych Info, Web of Science and Medline OVID databases. Search terms included the following: Implementation AND Knowledge Translation AND (Framework OR Model OR theory) AND (approach OR Strategy) AND (innovation OR evidence based). Only English language, full text and peer-reviewed articles were included. Titles and abstracts were initially reviewed to ensure a new framework was being described, rather than the application of an existing framework. However, if the article described a new combination of a number of frameworks, this article was included in the full text review as a novel framework. Figure 1 outlines our process of enquiry.

From this review, we identified that there were frameworks developed prior to 2011 that were not included in the Meyers et al review, [3] but could potentially be useful for our purposes. Snowball sampling was used to identify articles concerning previously developed implementation frameworks through existing reviews, reference lists, presentations and reports available online. We do not claim this search is exhaustive, but the approach reflects 
Figure 1: Flow diagram of the sources for the new implementation frameworks, from 2011 - June 2013

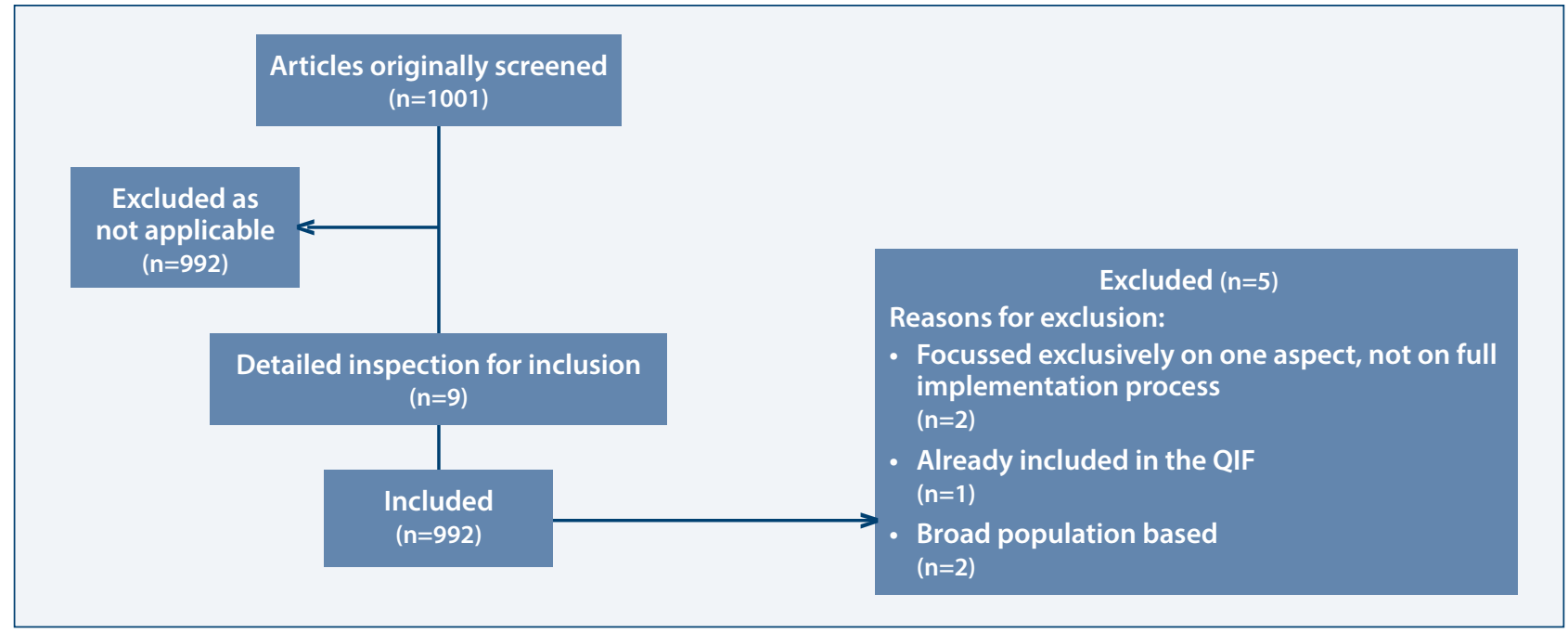

our focused attempts to include models that contained additional information that could add to the Meyers et al QIF. [3]

\section{Part 2}

Following the Part 1 search strategy, in mid 2014 a focus group discussion with five academics and two consultants was undertaken to analyse the QIF, and how this framework could be used in different contexts. The group met during a writing retreat over two days and consisted of authors of this paper and academic colleagues with an interest in implementation science. The members of the focus group worked through each step of choosing and implementing a hypothetical innovation using the QIF, to determine whether this framework provided sufficient guidance for the process of ongoing implementation and to identify gaps. For example, we considered the scenario where a new guideline for best practice in wound care had to be implemented in a community setting and applied the framework to this situation. We found that the framework was incomplete, as it seeks compliance, rather than routinisation into new practices. This led to further investigation of frameworks referenced by Meyers et al. [3] Searching for other frameworks within individual and social behavioural research was productive. [8,20-23] At this point, the PAR model $[13,24]$ was included to help individual clinicians reach the point at which not changing practice is no longer an option; called the 'tipping point'. Authors who published in these fields were identified by the academics involved in the focus group, to provide an initial sample of articles.

Snowball sampling was then undertaken to identify additional relevant articles through existing reviews, reference lists, presentations and reports available online.
Various checklists, guidelines and manuals developed for the operationalisation of frameworks were included in the search. Further, some authors were personally contacted for additional information, especially when it was found that further extensions of frameworks were under development.

All of the frameworks were then evaluated by the research team, through identifying constructs that influence implementation based on the strength of conceptual or empirical support, alignment with our own findings and experiences, and potential for measurement. Constructs were deemed useful if they addressed gaps within the QIF identified by the focus group.

The emphasis of Part 2 was to complement and extend concepts already included in the QIF in order to generate a framework that was more complete, and, more importantly, that could provide an operational guide that could be faithfully adhered to in different contexts. In total, 1001 articles were identified in the review, and after reviewing titles and abstracts, nine full text reviews were undertaken. The other studies were excluded as they were not relevant to the task, which was to support merging and improving through extension the existing frameworks.

\section{Results}

\section{An overview of 'where the literature is at'?}

The original QIF framework [3] includes 14 critical steps within four phases. The majority of the critical steps are within the pre-implementation period of Phases 1 and 2, aiming to prepare both the organisation and people for the implementation of change (e.g. innovations or updates to evidence-based practice). Phase 3 describes the ongoing structural requirements once implementation begins, and Phase 4 outlines improving future applications. 
Using the search strategy described above, the literature review from 2011 - 2013 resulted in nine relevant papers. After reading the full text, four studies had valuable ideas, additional to those already existing in the QIF and five were discarded because the QIF already included them, or they involved projects that did not lead to specific population intervention outcomes, rather providing information on broad, population-based innovations. The additional four frameworks generated from 2011 - 2013 added further detail in understanding the complexity of knowledge translation from research to standard practice, and emphasised:

- the need for communication,

- the importance of the role of leader champions,

- the importance of making the framework practical, and

- that the adoption of change is an individual behavioural issue.
Outlined in Table 1 are the different facets of the developed frameworks that would address some of the necessary components of implementation, however we also identified that critical aspects are missing from all the frameworks explored. In particular, both parts 1 and 2 of this study identified gaps in the areas of:individual and social behaviour, participatory action, operationalisation of the framework and evaluation of the framework. This is consistent with the current limited efficacy of implementation of change into practice. At this point, it is important to note that existing frameworks may well sufficiently promote uptake of evidence into practice, and the issues may lie more in flawed implementation of the frameworks. However, we suggest that frameworks must include sufficient information to support commitment to implementation, and that this is deficient in existing frameworks.

Table 1:

\begin{tabular}{|c|c|c|}
\hline AUTHORS AND FRAMEWORK/MODEL & DESCRIPTION & KEY QUESTIONS ANSWERED \\
\hline Rusly, Corner and Sun (2012) [25] & $\begin{array}{l}\text { Provides an in depth theoretical explanation } \\
\text { of the multidimensional and multilevel } \\
\text { characteristics of readiness for change. }\end{array}$ & 'Why' \\
\hline $\begin{array}{l}\text { Layde, Christiansen, Petersen, Guse, } \\
\text { Maurana and Brandenburg (2012) [26] } \\
\text { EDCHIP model }\end{array}$ & $\begin{array}{l}\text { A compilation of the CHIP [27] and RE-AIM } \\
\text { frameworks, [28] incorporating evidence- } \\
\text { based public health frameworks in the } \\
\text { planning phase, translating evidence-based } \\
\text { interventions into community practice and } \\
\text { emphasising communication with key } \\
\text { stakeholders. }\end{array}$ & 'What and How' \\
\hline $\begin{array}{l}\text { Palmer and Kramlich (2011) [29] } \\
\text { MKIT }\end{array}$ & $\begin{array}{l}\text { Provides an overview of the integration } \\
\text { and translation of innovation in the } \\
\text { implementation stages of knowledge } \\
\text { generation, through a circular process, } \\
\text { which indicates the ongoing nature of } \\
\text { evidence-based practice uptake. } \\
\text { Leaders within organisations must be } \\
\text { transformational in order to act as catalysts } \\
\text { for change for the framework to be } \\
\text { successful. }\end{array}$ & 'What' \\
\hline Packard (2013) [30] & $\begin{array}{l}\text { Focuses on individual human behaviour, } \\
\text { focusing on readiness factors, capacity } \\
\text { factors and change tactics. }\end{array}$ & 'How' \\
\hline
\end{tabular}


Balancing Yin and Yang: the development of a framework using Participatory Action Research for the Translation and Implementation (Part 1) of new practices

Table 2:

\begin{tabular}{|l|l|}
\hline FRAMEWORK & DETAILS OF FRAMEWORK \\
\hline The Interactive Systems Framework (ISF) & $\begin{array}{l}\text { Provides specific detail relating to operationalising the QIF's first three } \\
\text { phases to improve implementation fidelity. }\end{array}$ \\
\hline $\begin{array}{l}\text { The Promoting Action on Research } \\
\text { Implementation in Health Services } \\
\text { (PARiHS - revised version) framework }\end{array}$ & $\begin{array}{l}\text { Includes tools to promote fidelity of implementation, however it is, as yet, } \\
\text { not comprehensive. [31] }\end{array}$ \\
\hline $\begin{array}{l}\text { The Consolidated Framework for } \\
\text { Implementation Research (CFIR) }\end{array}$ & $\begin{array}{l}\text { Consistent with those developed in the original PARiHS model, [32] but } \\
\text { differing in splitting the context into inner and outer settings, and adding } \\
\text { a focus on characteristics of individuals. [33] The usefulness of this } \\
\text { framework lies in the idea of making the framework context specific. } \\
\text { In addition, the authors developed a useful matrix of constructs taken } \\
\text { from Greenhalgh et al.'s (2004) seminal work, [34] which helped facilitate } \\
\text { the generation of their own new framework. }\end{array}$ \\
\hline $\begin{array}{l}\text { The Availability, Responsiveness and } \\
\text { Continuity (ARC) framework }\end{array}$ & $\begin{array}{l}\text { Uses intervention strategies at the organisational and the inter-organisational } \\
\text { levels, and adds to the QIF by adding a clear role for knowledgeable } \\
\text { external agents to be involved in the process. }\end{array}$ \\
\hline $\begin{array}{l}\text { The Quality Enhancement Research } \\
\text { Initiative (QUERI) }\end{array}$ & $\begin{array}{l}\text { Incorporates the phases necessary to assure adequate development, } \\
\text { refinement, evaluation, and assessment of innovative evidence-based } \\
\text { implementation programs and strategies. It involves six steps, with the } \\
\text { selection of the issue including an aspect of prioritisation using a formal } \\
\text { ranking procedure to guide identification of the area of highest need. }\end{array}$ \\
\hline
\end{tabular}

Table Note: Adapted from the Meyers et al [3] review

\section{Investigation of frameworks used to develop the QIF}

The frameworks identified from the Meyers et al [3] review that were investigated are included in Table 2.

By combining the tools described in Table 2, the QIF has become a comprehensive tool for the translation and implementation of health innovations. However, the focus group's testing of the model on virtual projects revealed that the current QIF framework pays inadequate attention to individual and social behaviour. This is important because interactions in healthcare settings frequently occur between normally disparate and autonomous professionals.

\section{Existing behavioural change frameworks and the PARTI framework}

Due to the need to explain behaviour change in implementation, the authors searched the literature and identified the work completed by Michie et al (2005). [16] This team synthesised the literature in behaviour change to develop the Theoretical Domains Framework (TDF). This model proposed 12 domains contributing to the decisions people made to implement improvements or otherwise change their practice. These domains were: (1) knowledge, (2) skills, (3) social/professional role and identity, (4) beliefs about capabilities, (5) beliefs about consequences, (6) motivation and goals, (7) memory, attention and decision processes, (8) environmental context and resources, (9) social influences, (10) emotion regulation, (11) behavioural regulation, and (12) nature of the behaviour.

Cane et al (2012) [9] then extended this model to 14 domains as a result of a systematic evaluation using a three stage sorting technique. However, upon evaluating Cane et al's (2012) [9] and Mitchie et al's (2005) [16] models as a result of developing a questionnaire for measuring the model, Huijg et al (2014) [10] found more support for Michie et al's (2005) [16] model than Cane et al's (2012) [9] model. Therefore, the TDF was identified as an important inclusion in our implementation framework.

The use of checklists was also deemed important for operationalisation due to the value in providing a simple tool for change champions to communicate the content and sequence of changes, and to embed the desired changes in operational routines. [35] The intent of the checklist is to enable individuals and teams to work together, be involved and lead to improved clinician engagement, translation of evidence-based innovation and cause practical change. 
Table 3:

\begin{tabular}{|l|l|}
\hline AUTHORS & CHECKLIST \\
\hline Chinman, Imm and Wandersman (2004) [14] & Getting To Outcomes (GTO'M). \\
\hline Guldbrandsson (2008) [36] checklist & 'From news to everyday use: The difficult art of implementation'. \\
\hline $\begin{array}{l}\text { US Department of Healthcare and } \\
\text { Human services }\end{array}$ & Agency for Healthcare Research and Quality (AHQR). [17] \\
\hline $\begin{array}{l}\text { New South Wales Clinical Excellence } \\
\text { Commission (CEC) }\end{array}$ & $\begin{array}{l}\text { Enhancing Project Spread and Sustainability - A Companion } \\
\text { to the 'Easy Guide to Clinical Practice Improvement'. [18] }\end{array}$ \\
\hline
\end{tabular}

\section{Existing checklists and the PARTI framework}

The use of checklists is becoming a valuable addition to change implementation models. We reviewed different questionnaires for implementation. [14,17-19,36,37] We included checklists shown in Table 3.

The end result was a checklist of questions that focuses those who are implementing innovations to the context and work at hand. In this way, there is an active process of implementation to facilitate the progression of implementation. While this checklist was more helpful to operationalise implementation, the authors identified that there was still no component that 'hooked in' practitioners, that is, there was no emotional element that would ensure active 'buy in' by practitioners into the process. Thus there was a need to include some introspective questions in order to ensure that practitioners reflected on what they did, and more importantly, 'why'.

Human behaviour is an area that is not well addressed in current implementation frameworks and as such draws attention to the importance of intrinsic volitions and sustained changed behaviour. Intrinsic volition includes those aspects related to personal motivation and wanting to change behaviour, and then motivations to sustain this change, trusting that the new behaviour is better and thus supporting the adoption of alternate behaviour(s). These include an emphasis on reflection of the risks of not changing behaviour when evidence is presented. Therefore our implementation framework was influenced also by psychologism.

Psychologism combines the study of psychology and philosophy or logic [38] and encompasses both the inferences people should make, and the conclusions they actually reach and act upon. We considered the personal, social and profession-based aspects of organisational change and included prompts for individual introspection about the need for change and the impacts of change for patients and clinicians.
The inclusion of these previously neglected factors, are proposed to instigate an increased commitment to change, clinician buy-in and encourage change fidelity. To maximise this impact, we developed a questionnaire, shown in Appendix 1, to encourage introspection at each stage of the change process, including questions about: need; readiness; relevance; and agreement for change. The aim of these reflective questions is to develop awareness that the combination of the risks of doing nothing and the potential for continued adverse events to act as a tipping point for all stakeholders to commit to change.

Figure 2: PARTI framework [adapted from 39, p.217]

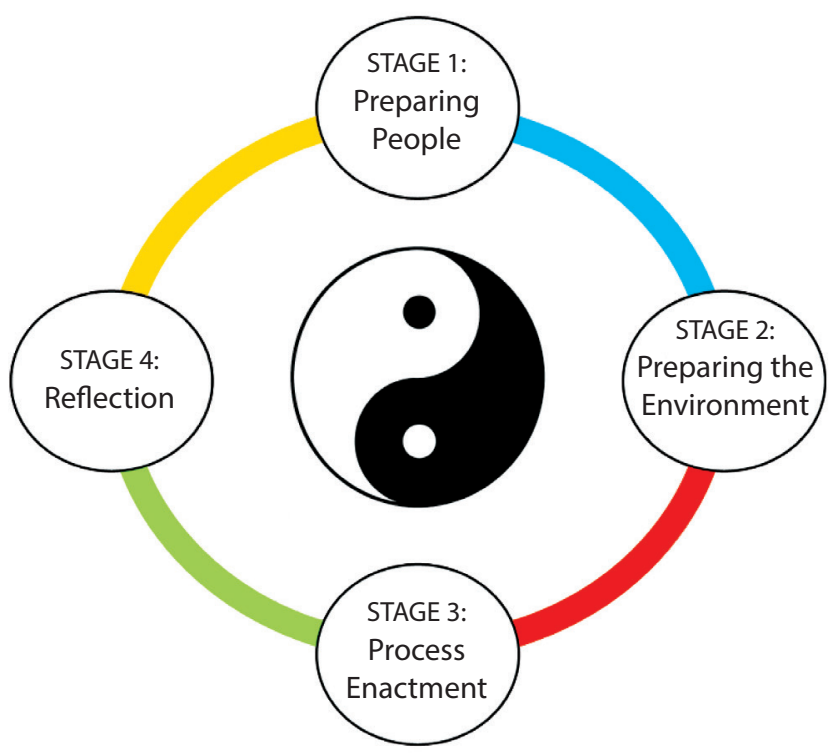

In our proposed framework, we propose a four-stage process, each with a range of questions to encourage constructive introspection from individual, group and organisational membership perspectives. Each stage is linked in a circle, indicating the continuity of the model of change, which is never ending. Central to each is the interaction between positive and negative influences (Yin and Yang) creating a harmonious environment, in which change takes place, is adopted, implemented and evaluated. For this harmony to 
occur, introspection is needed. A discussion of each stage is now provided and the questionnaire with introspective questions that must be completed before beginning the next stage is provided in Appendix 1.

\section{Stage one: Preparing people - stakeholder salience, champion identification, needs assessment and resource assessment.}

This stage includes identifying one or more change champions along with those stakeholders with the highest salience, developing a shared vision, creating an environment of readiness for social interaction and exchange, and undertaking a resource and risk assessment. Some sample introspection questions in this stage and can include: 'Who in the organisation will 'lead the charge' for this project?' 'Who has the ability to effectively promote its value to others?'

\section{Stage two: Preparing the environment for embedding changes using PAR - imagining the ideal state.}

This stage initiates the social interaction and exchange environment that will support a PAR approach to engage key stakeholders in the process. This involves preparatory training and implementation and monitoring of the identified changes. Stakeholder tipping points are analysed in this stage and stakeholders are encouraged to undertake regular introspection periods to ensure actual actions are congruent with agreed goals. Actions can include understanding the current state, developing stakeholder goal congruence, a needs assessment and establishment of an implementation team with clearly defined specific roles. This leads to identification of opportunities for improvement to policies and procedures, structures, processes, access, support and training among others. A critical reference group is established to monitor (pre-empt problems and address any potential issues) and undertake concurrent evaluation of the changes (a supportive feedback mechanism).

Some sample introspection questions can include: 'Where are the data showing there are gaps between best practice and current care?' 'How are things done now?'

\section{Stage three: Process enactment (ie doing it)}

This stage includes monitoring (pre-empting problems and addressing any potential issues) and undertaking concurrent evaluation (supportive feedback mechanisms) as part of PAR. An example of introspection questions can be: 'Has there been evidence, or good reasons provided that the change will address staff concerns?'

\section{Stage four - Reflection and assessing the new state.}

This stage includes reflection on what has been done (considering, interpreting and documenting) and a reflection on lessons learnt. It looks at what problems still exist/have emerged and identifies whether these need addressing by returning to stage one, or whether an issue identified by the earlier needs assessment can now be addressed. This stage also includes prioritising (recognition that there are multiple possibilities and looking at what can/ still needs to be changed) and assessing the new state of affairs (whether the new state is what you wanted to achieve and/or whether new problems have been generated). Some sample questions can include: 'What is working and what isn't?' 'Do changes to implementation plans need to be made?'

\section{Discussion and conclusion}

Unpredictable implementation fidelity and inadequate consideration of the motivations and behaviours to commit to change of individuals within groups and organisations are addressed through the specific guidance provided by the PARTI checklist. The development of the PARTI framework has been supported by a series of 'thought experiments' in which we tested the completeness and probability of success using a range of health innovation implementation experiences that have either been publicly reported or we have directly experienced. These include tele-health, patient journey re-design, developing new products for health services settings and continuous quality improvement program implementation.

The PARTI framework has been explicated and operationalised in the following stages: pre-implementation planning and creating the implementation environment, embedding processes, doing it, reflection and evaluation. The next stage in the research will be to switch from a rationalist, theoretical approach and to empirically test the usefulness of the framework [40] in order to see if it supports effective change in a range of high and low acuity health settings (e.g. aged care, home nursing support, hospital wards). Following that, comparisons of the efficacy of the PARTI framework and other frameworks developed to improve the dissemination and uptake of evidence-based practice would be performed.

This paper makes important contributions to the literature. First, the PARTI framework is novel in its extension of existing assessment tools by including operational constructs that are linked to theoretical frameworks, thereby enabling their practical application. Second, it introduces consistent reflective practices throughout the implementation lifecycle that encourage individuals to consider personal motivation and change behaviours. This in turn highlights 
the importance of identifying participants'tipping point and preparing them and the environment for proposed changes, where the tipping point represents the point at which an individual moves from inertia to motion. This includes finding their compelling rationale for change, supporting effective change and then embedding the changed state into individual, professional and organisational practices. In essence, the introspection questions will assist participants commit to the change. Further, and most importantly, clear guidance is provided to implementers of innovations by introducing a set of checklists, to ensure that what is being implemented is as close to that planned as possible - an important aspect often not considered in implementation research [41] and an aspect that inhibits change fidelity. This should allow those aiming to improve uptake of evidence into practice to be more likely to reach a successful outcome by considering a balanced approach of commitment (Ying) and fidelity (Yang) at every stage. Finally, PAR is being used as a method to operationalise the framework, as it facilitates the move from theory driving practice to practice driving theory, thus making it truly cyclical.

Consequently, this paper makes significant contributions to the literature on implementation frameworks. In doing so, it suggests that researchers need to consider the human element of translating research into practice. That is, while it is well known that evidence alone does not change practice, understanding what makes people commit to and enact change sustainably at an individualistic level may make implementing research into practice more successful in the future. This paper has focused on the individual response when implementing new practices. However, organisational routinisation of new practices also requires group and organisational reactions to the design and implementation of change. The real challenge for organisations is to capitalise on individual momentum and harness the energy to carry out organisational transitions. This is the objective of future work.

\section{Competing interests}

The authors declare that they have no competing interests.

\section{References}

1. WHO. Knowledge Translation on Ageing and Health: a framework for policy development 2012. Geneva: WHO; 2012.

2. IOM. Best care at lower cost: the path to continuously learning health care in America. Washington, DC: 2012.

3. Meyers DC, Durlak JA, Wandersman A. The Quality Implementation Framework: a synthesis of critical steps in the implementation process. Am J Community Psychol. 2012.

4. Graham ID, Tetroe J, Group KTR. Some theoretical underpinnings of knowledge translation. Academic Emergency Medicine. 2007;14:936-41.

5. Grimshaw J, Thomas R, MacLennan G, Fraser C, Ramsay C, Vale L, et al. Effectiveness and effici $\neq$ ency of guideline dissemination and implementation strategies. Health Technol Assess. 2004;8(6):iii-72.

6. Eastabrooks C. Guide to Knowledge Translation Theory. J Contin Educ Health Prof. 2006;26:25-36.

7. Brehaut JC, Eva KW. Building theories of knowledge translation interventions: use the entire menu of constructs. Implement Sci. 2012;7(114).

8. Michie S, Johnston M, Francis J, Hardeman W, Eccles M. From theory to intervention: mapping theoretically derived behavioural determinants to behaviour change techniques. Appl Psychol. 2008;57(4):660-80.

9. Cane J, O'Connor D, Michie S. Validation of the theoretical domains framework for use in behaviour change and implementation research. Implement Sci. 2012;7(37).

10. Huijg JM, Gebhardt WA, Crone MR, Dusseldorp E, Presseau J. Discriminant content validity of a theoretical domains framework questionnaire for use in implementation research. Implement Sci. 2014;9(11).

11. Wandersman A, Chien VH, Katz J. Toward an evidence-based system for innovation support for implementing innovations with quality: tools, training, technical assistance, and quality assurance/ quality improvement. Am J Community Psychol. 2012;50:445-59.

12. Rogers EM. Diffusion of innovations. 5th ed. New York, NY: The Free Press; 2003.

13. Wadsworth Y. Building in research and evaluation: human inquiry for living systems. Sydney: Action Research Press, Hawthorn and Allen \& Unwin; 2010.

14. Chinman M, Imm P, Wandersman A. Getting to outcomesTM 2004: promoting accountability through methods and tools for planning, implementation, and evaluation. . Santa Monica, CA: RAND Corporation; 2004.

15. French SD, Green SE, O'Connor DA, McKenzie JE, Francis JJ, Michie S, et al. Developing theory-informed behaviour change interventions to implement evidence into practice: a systematic approach using the Theoretical Domains Framework. Implement Sci. 2012;7(38).

16. Michie $S$, Johnston $M$, Abraham C, Lawton R, Parker D, Walker A. Making psychological theory useful for implementing evidence based practice: a consensus approach. Qual Saf Health Care. 2005;14(1):26-33.

17. AHQR. Will it work here? A decision maker's guide to adopting innovations. Rockville, MD: Services USDoHaH; 2008.

18. CEC. Enhancing project spread and sustainability - a companion to the 'Easy Guide to Clinical Practice Improvement'. Sydney: CEC. Sydney: Clinical Excellence Commission; 2008.

19. MassTAPP. Partnerships for Success II: Guidance Document. Massachusetts: MA Department of Public Health, Bureau of Substance Abuse Services; 2012. 
20. Michie $S, A b r a h a m ~ C$. Identifying techniques that promote health behaviour change: Evidence based or evidence inspired? Psychology and Health. 2004;19:29-49.

21. Michie S, Ashford S, Sniehotta FF, Dombrowski SU, Bishop A, French DP. A refined taxonomy of behaviour change techniques to help people change their physical activity and healthy eating behaviours: The CALO-RE taxonomy. Psychol Health. 2011; 26(11):1479-98.

22. Michie S, Hyder N, Walia A, West R. Development of a taxonomy of behaviour change techniques used in individual behavioural support for smoking cessation. Addictive Behaviors. 2011; 36(4):315-9.

23. Kotter JP, Cohen DS. The Heart of Change: Real-life stories of how people change their organizations. Boston, Massachusetts: Harvard Business School Press; 2002

24. Wallerstein N, Duran B. Community-based participatory research contributions to intervention research: the intersection of science and practice to improve health equity. Am J Public Health. 2010; 100(Supplement 1):S40-6.

25. Rusly FH, Corner JL, Sun P. Positioning change readiness in knowledge management research. Journal of Knowledge Management. 2012;16(2):329-55

26. Layde P, Christiansen A, Peterson D, Guse C, Maurana C, Brandenburg T. A model to translate evidence-based interventions into community practice. Am J Public Health. 2012;102(4):617-24.

27. Institute of Medicine, Health CoUPMtIC. Improving health in the community: a role for performance monitoring. Washington DC: 1997.

28. VirginiaTech. Re-aim Blacksburg, Virginia2013 [updated 2013; cited 201314 June]. Available from: http://www.re-aim.hnfe.vt.edu/ index.html.

29. Palmer D, Kramlich D. An introduction to the multi-system model of knowledge integration and translation (MKIT). Adv Nurs Sci. 2011;34(1):29-38.

30. Packard T. Organizational change: a conceptual framework to advance the evidence base. Journal of Human Behavior in the Social Environment. 2013;23(1):75-90.

31. Rycroft-Malone J, Seers K, Chandler J, Hawkes CA, Crichton N, Allen $\mathrm{C}$, et al. The role of evidence, context, and facilitation in an implementation trial: implications for the development of the PARIHS framework. Implement Sci. 2013;8(28)

32. Rycroft-Malone J, Seers K, Crichton N, Chandler J, Hawkes CA, Allen $\mathrm{C}$, et al. A pragmatic cluster randomised trial evaluating three implementation interventions. Implement Sci. 2012;7(80).

33. Damschroder LJ, Aron DC, Keith RE, Kirsh SR, Alexander JA Lowery JC. Fostering implementation of health services research findings into practice: a consolidated framework for advancing implementation science. Implement Sci. 2009;4(50).

34. Greenhalgh T, Robert G, Macfarlane F, Bate P, Kyriakidou O. Diffusion of innovations in service organizations: systematic review and recommendations. Milbank Q. 2004;82(4):581-629.

35. Gawande A. The checklist manifesto : how to get things right. New York, New York Metropolitan Books; 2010.

36. Guldbrandsson K. From news to everyday use: the difficult art of implementation. Stockholm: Swedish National Institute of Public Health; 2008.

37. Albert D, Fortin R, Herrera C, Riley B, Hanning R, Lessio A. Strengthening chronic disease prevention programming: the toward evidence-informed practice (TEIP) program evidence tool. Preventing Chronic Disease. 2013;10:E87.
38. Perla RJ, Provost LP, Parry GJ. Seven propositions of the science of improvement: exploring foundations. Qual Manag Health Care. 2013;22(3):170-86.

39. Worley CG, Mohrman SA. Is change management obsolete? Organizational Dynamics. 2014;43(3):214-24.

40. Newton W. Rationalism and empiricism in modern medicine. Law and contemporary problems. 2001;64(4):299-316.

41. Keith RE, Hopp FP, Subramanian U, Wiitala W, Lowery JC. Fidelity of implementation: development and testing of a measure. Implement Sci. 2010;5(99). 


\section{Appendix 1}

Implementation checklist

\begin{tabular}{|c|c|}
\hline $\begin{array}{l}\text { STAGE 1: } \\
\text { Pre-implementation planning }\end{array}$ & $\begin{array}{l}\text { - Is there an acknowledged need for change? } \\
\text { - Who in the organisation will 'lead the charge' for this project? } \\
\text { - Who has the ability to effectively promote its value to others? } \\
\text { - Who has the respect of others and authority to make decisions? } \\
\text { - Which stakeholders are recognised as holding all three salient attributes } \\
\text { - power, legitimacy and urgency? } \\
\text { - What does the organisation want to achieve? } \\
\text { - What resources do we currently have? } \\
\text { - Are there any known risks associated with the area to be changed? } \\
\text { Introspective questions on commitment and fidelity: } \\
\text { - How will we get people to commit before moving onto next stage? } \\
\text { - What is my responsibility to ensure sustainable health system? } \\
\text { - Do I care about the overall health system and its sustainability? } \\
\text { - What is my moral responsibility in terms of benevolence? } \\
\text { And doing good for those in my care? }\end{array}$ \\
\hline $\begin{array}{l}\text { STAGE } 2 \\
\text { Creating the implementation } \\
\text { environment and Embedding } \\
\text { the processes, PAR }\end{array}$ & $\begin{array}{l}\text { - How are things done now? } \\
\text { - What are the opportunities for improvement? } \\
\text { - What data is available? } \\
\text { - What else is needed? } \\
\text { - Which issues have the available resources and capacity to be addressed? } \\
\text { - Is there a known solution that would work here? } \\
\text { - } \quad \text { Are we ready? } \\
\text { - Who will do what? } \\
\text { - What is/are the priority/ies? } \\
\text { - Where are the data showing there are gaps between best practice and } \\
\text { - } \text { - Whatrent care? } \\
\text { - What resources are already available to address the identified needs? } \\
\text { - Has there been evidence, or good reasons provided that the change } \\
\text { - Will address staff concerns? } \\
\text { - What are the opportunities for improvement? } \\
\text { Introspective questions on commitment and fidelity: How will we get } \\
\text { people to commit before moving onto next stage? } \\
\text { - What are your deeper hopes, values, purposes and intentions? } \\
\text { - What could realise them? } \\
\text { - What will the future look like if no changes are made now? } \\
\text { - Is the risk of changing my behaviour greater than the risks associated } \\
\text { with doing the same as I do now? } \\
\text { or do I suspect work will be shifted my way? }\end{array}$ \\
\hline
\end{tabular}


Appendix 1 continued

\begin{tabular}{|c|c|}
\hline STAGE 3 & \\
\hline Process enactment & $\begin{array}{l}\text { - Has there been evidence, or good reasons provided that the change will } \\
\text { address staff concerns? } \\
\text { - Are the outcomes sufficiently improved for the amount of work needed } \\
\text { to make the changes? } \\
\text { - Are we on the right track? } \\
\text { - Are the patients satisfied? } \\
\text { - Is it helping? Do you feel you are doing better work this way? } \\
\text { Introspective questions on commitment and fidelity: How will we get } \\
\text { people to commit before moving onto next stage? } \\
\text { - Can I give myself permission for the change to take place (passively)? } \\
\text { - Can I support this change? Can I be a leader of this change (actively)? } \\
\text { - Can I step forward to assist the implementation of change as quickly } \\
\text { as possible? }\end{array}$ \\
\hline $\begin{array}{l}\text { STAGE } 4 \\
\text { Evaluation and reflection }\end{array}$ & $\begin{array}{l}\text { - What is working and what isn't? } \\
\text { - Do changes to implementation plans need to be made? } \\
\text { - } \quad \text { Is it helping? Do you feel you are doing better work this way? } \\
\text { - What else is needed? } \\
\text { - Have we achieved what we set out to achieve? If not, why not? } \\
\text { - What do we now know that we did not know prior to this change } \\
\text { initiative? } \\
\text { - What does the new innovation make redundant? } \\
\text { - Where else does change need to happen to make this work better? } \\
\text { - } \quad \text { Is the innovation being implemented as originally planned? } \\
\text { - Have you addressed the original identified need? } \\
\text { - Have the original issues that needed to be addressed been improved? } \\
\text { - Have new problems been identified? } \\
\text { - How will we get people to commit before moving onto next stage } \\
\text { (or innovation)? } \\
\text { Introspective questions on commitment and fidelity: } \\
\text { - Do I like seeing changes fail?( -I told you so...)? } \\
\text { - Is it my personal preference to keep working harder and not make any } \\
\text { changes? } \\
\text { - What have I done to make this change successful? } \\
\text { - How could I have done differently? What was my commitment to success? } \\
\text { How did I manage expectations? } \\
\text { What will I do differently next time. }\end{array}$ \\
\hline
\end{tabular}

